\title{
Manufacturing and Characterization of Jute/PP Thermoplastic Commingled Composite
}

\author{
Bárbara Righetti Souza ${ }^{a *}$, Ricardo Mello Di Benedetto ${ }^{a}$, Denise Hirayama ${ }^{a}$, Olívia de Andrade
}

Raponi $^{a}$, Lorena Cristina Miranda Barbosa ${ }^{a}$, Antonio Carlos Ancelotti Junior ${ }^{a}$

${ }^{a}$ Mechanical Engineering Institute, Universidade Federal de Itajubá, Av. BPS, 1303, Itajubá, MG, Brazil

Received: January 17, 2017; Revised: June 08, 2017; Accepted: September 17, 2017

\begin{abstract}
The commingled technology is a promising technique for the manufacture of composites reinforced with natural fibers. This study presents the development, processing and basic characterization of a long fiber Jute/Polypropylene (Jute/PP) commingled composite. The Jute/PP fabric was produced in a handloom and the composite was consolidated by compression molding. The PP matrix was chemically and thermally characterized to certify its chemical composition and define its melting and crystallization temperatures. The degradation behavior of jute fibers was also studied by Friedman's kinetic isoconversional model using thermogravimetric analyses (TGA). The mechanical properties of jute reinforcement and Jute/PP composite were characterized by tensile strength tests and by fractographic study of the fracture surfaces. Its tensile strength $(44.62 \pm 6.02 \mathrm{MPa})$ and elasticity modulus $(7.10 \pm 2.34 \mathrm{GPa})$ are approximate to the ones obtained by other processing techniques, suggesting that the developed commingled process can work as a low cost and practical alternative methodology for manufacturing of more sustainable composites in industries.
\end{abstract}

Keywords: Thermoplastic commingled composite, Jute/PP preform, Compression molding, Natural fiber

\section{Introduction}

In the two last decades, the commingled thermoplastic composites have settled effectively as versatile materials with economical attraction to the manufacturing of automotive and aeronautics industries products ${ }^{1}$. The term commingled refers to materials that contain both reinforcement and matrix polymer in the same fabric (or tape) used in the manufacturing of structural thermoplastic composites ${ }^{2,3}$. One of the main advantages of using commingled fabrics is the molding capacity and flexibility, which allows the conformation of the fabric in complex geometries ${ }^{4}$.

The use of commingled thermoplastic composites comprises some technological challenges concerning the wetting and impregnation of the fibers by the matrix during the consolidation process, since thermoplastic resins have higher viscosity than thermoset resins ${ }^{5}$. Thermoplastic composites consolidation involves the melting of the polymer matrix by applying temperature and pressure, during a determined period. For this reason, the final composite quality is strongly dependent on the consolidation parameters, which leads to the finding of many literature studies focusing on thermoplastics consolidation techniques and parameters ${ }^{6,7}$.

The growing interest in research and innovation involving natural fiber composites is mainly due to its low weight associated with moderate mechanical properties ${ }^{8}$ when compared to synthetic fibers. Also, natural fibers are biodegradable, low in cost and easy to obtain ${ }^{9,10}$. These properties are already being explored by some industries sectors, like the automotive that is already using natural fiber composites in car inner linings and internal structural devices $^{10,11}$.

The fabric manufacturing by commingled technique presents some interesting advantages for composite structures processing, like easy storage and manipulation, which allows its combination with well-established processes such as compression molding ${ }^{2,3}$. In general, commingled technology provides a more homogenous fiber dispersion with good interfacial bonding, reducing its agglomeration tendency ${ }^{9}$, when compared to composites made of thermoplastic powder or thin films. A possible commingled architecture is the one in which the warp direction is made of natural fiber reinforcements and the weft direction is made of thermoplastic matrix yarns. From a mechanical properties standpoint, another advantage of commingled technology over other mixing processes, like injection molding, is that this technology can prevent shear forces from acting on the fibers and causing defects such as splitting and peeling, when natural fibers are used as reinforcement ${ }^{11}$.

The polypropylene matrix and natural jute fiber reinforcements (Jute/PP) is one type of composite material composition that can measure up to the advantages described above. This sort of material presents good qualities for further application in manufacturing automotive parts and components ${ }^{2,3}$. For these reasons, the study and development of simple processing methodologies can lead to the manufacturing of good quality Jute/PP composites, which is highly attractive to industries. 
The materials used on the weaving of the Jute/PP commingled fabric require some specific characteristics such as: continuous reinforcement fiber and PP matrix yarn and high malleability in order to create a compacted fabric, avoiding voids and delamination after the laminate processing ${ }^{12}$. The challenge in developing a commingled Jute/PP fabric as a preform for composite manufacturing is also to adapt it to the required conditions of weaving industry. Therefore, the present work proposes the manufacture of a Jute/PP commingled composite focusing on the development of a simple manufacturing technology for composite materials that can also contribute in terms of sustainability and reuse.

\section{Experimental Procedures}

\subsection{Materials}

The jute yarn was supplied by a Brazilian local manufacturer in the form of continuous reinforcement. The tow is composed of numerous twisted microfilaments and its total average diameter is approximately $0.93 \mathrm{~mm}$ and weight of $0.41 \mathrm{~g} / \mathrm{m}^{2}$. No superficial treatments were performed in the jute fiber. The PP yarn used in the fabrication of the commingled fabric is usually used for bag sewing, in view of its high strength and malleability. It was purchased from Grafix and has a $0.25 \mathrm{~mm}$ diameter and $0,78 \mathrm{~g} / \mathrm{m}^{2}$.

\subsection{Matrix characterization}

Chemical analyses were carried out in the commercial textile yarn to confirm its chemical composition (polypropylene). Attenuated total reflection (ATR) Fourier-transform infrared spectra (FTIR) were performed on Perkin-Elmer Spectrum 100 spectrophotometer in the wavenumber range of 4000 to $650 \mathrm{~cm}^{-1}$ with $\mathrm{ZnSe}$ conical tip.

The polymer was submitted to a differential scanning calorimetry (DSC) analysis to identify its melting and crystallization temperatures, the enthalpies involved in both transitions. This analysis was performed in a DSC TA Instruments Q20 analyzer with RCS40 cooling unit based on the ASTM standard for Modulated Temperature Differential Scanning Calorimetry ${ }^{13}$. DSC analysis parameters are summarized in Table 1.

Table 1. DSC parameters. Bibliography source: Author.

\begin{tabular}{clcc}
\hline Run & Atmosphere & $\begin{array}{c}\text { Heat rate } \\
\left({ }^{\circ} \mathbf{C} / \mathbf{m i n}\right)\end{array}$ & $\begin{array}{c}\text { Temperature } \\
\text { range }\left({ }^{\circ} \mathbf{C}\right)\end{array}$ \\
\hline $\mathbf{1}$ & Synthetic Air & 10 & $30-250$ \\
$\mathbf{2}$ & Synthetic Air & 20 & $250-30$ \\
\hline
\end{tabular}

\subsection{Jute fiber tow characterization}

The jute fiber degradation behavior was characterized by TGA, performed in a Mettler Toledo AE 240 TG. In order to determine the kinetic parameters by Friedman's isoconversional kinetic model, samples of approximately $10 \mathrm{mg}$ of jute were placed in alumina sample pans and submitted to heating cycles from $0^{\circ} \mathrm{C}$ to $800^{\circ} \mathrm{C}$ in three different heating rates of $5^{\circ} \mathrm{C} / \mathrm{min}, 10^{\circ} \mathrm{C} / \mathrm{min}$ and $15^{\circ} \mathrm{C} / \mathrm{min}$.

The degradation kinetics in polymers can be described by Eq. $1^{14}$, in which $\alpha$ represents the degradation degree, $t$ is the time, $\mathrm{k}(\mathrm{T})$ is the temperature $(\mathrm{T})$ dependent constant and $f(\alpha)$ is the reaction model.

$$
\frac{d \alpha}{d t}=k(T) f(\alpha)
$$

The $\alpha$ values can be experimentally determined by TGA and express the relative mass loss. In general, the constant $\mathrm{k}(\mathrm{T})$ is well described by the Arrhenius equation (Eq. 2), in which Ea represents the activation energy, $\mathrm{R}$ is the gas constant and $\mathrm{A}$ is the pre-exponential factor.

$$
k(T)=A e\left(\frac{-E_{a}}{R T}\right)
$$

The multiplication of the pre-exponential factor by the reaction model will henceforth be denominated as $\mathrm{A} \alpha$ $\left(\mathrm{A}_{\alpha}=\mathrm{A} . \mathrm{f}(\alpha)\right)$. Then, the Eq. 3 can be obtained by replacing Arrhenius equation in Eq. 1

$$
\frac{d \alpha}{d t}=A_{\alpha} e\left(\frac{-E_{a}}{R T}\right)
$$

The isoconversional or model free kinetics model is based on two main concepts: (i) the kinetic development is based on Equations 1 and 3, (ii) the Arrhenius parameters can be determined from a minimum of three TGA dynamic analyses in different heating rates.

The Friedman's model ${ }^{15}$ allows the calculation of the kinetic parameters, such as activation energy (Ea) and preexponential $(\mathrm{A} \alpha)$, which are obtained by the linearization of the degradation degree rate $(\mathrm{d} \alpha / \mathrm{dt})$ versus the inverse temperature $(1 / \mathrm{T})$ graphic, for each degree of degradation $(\alpha)$, based on Eq. 4 , in which $-\mathrm{Ea} / \mathrm{R}$ and are equivalent to the line's equation slope and intersection, respectively.

$$
\ln \left(\frac{d \alpha}{d t}\right)=\ln A_{\alpha}-\frac{E}{R T}
$$

Friedman's isoconversional method also allows the forecast of the degradation degree as a function of time for a given temperature, using the kinetic parameters obtained as described above. This forecast was obtained by the Eq.5, as follows.

$$
\alpha=A_{\alpha} \exp \left(-\frac{E}{R T}\right) t
$$

These calculations were made in order to define the process window for the Jute/PP composites, focusing on the time and temperature necessary to provide the melt of the matrix without reaching a damaging degradation degree on the jute fiber. To do so, degradation study results were also 
combined with DSC results obtained from the PP matrix thermal characterization.

The reinforcing jute fibers have also been evaluated by the tensile tests according to ASTM C1557-03 ${ }^{16}$, to determinate the tensile strength and modulus of elasticity of jute yarn. The testing was conducted on a universal testing machine EMIC DL300 using 15 samples of jute yarn, individually, with $500 \mathrm{kgf}$ load cell and test speed of $0.5 \mathrm{~mm} / \mathrm{min}$. For performing these mechanical tests, the average diameter of the jute fiber was measured by Zeiss Jenavert optical microscope with 50x of magnification.

\subsection{Weaving}

To obtain a unifabric type ${ }^{2}$ commingled fabric, a small and simple handloom was developed using a specific computeraided design (CAD) program as shown in the Figure 1(A). The woven architecture obtained was a unidirectional fiber reinforced with jute fiber warp direction and the polypropylene yarn as weft direction (Figure 1B). For each manipulation of the comb, four trailers of the weft ${ }^{17}$ were inserted. The final appearance of the developed preform is shown in Figure 2.

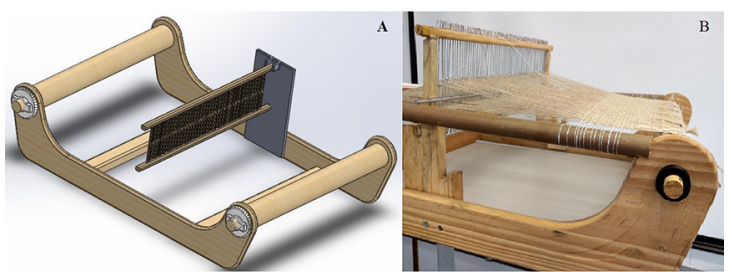

Figure 1. Design of the loom. (A) Diagram of the handloom. (B): Handloom. Bibliographic source: Author.

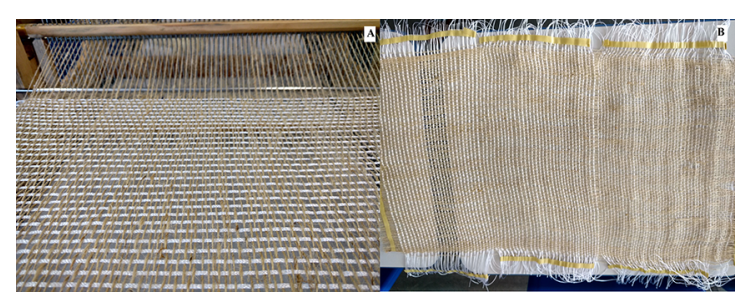

Figure 2. Commingled unifabric Jute/PP. (A) Fabric at the beginning of weaving. (B): Finished jute/PP fabric. Bibliographic source: Author.

\subsection{Composite processing}

The flat composite preforms of Jute/PP ( $4 \mathrm{~mm}$ thick) was manufactured by compression molding process. Nine layers of unifabric commingled Jute/PP were cut in $0^{\circ}$ direction and staked in a flat metal mold. To ensure a uniform matrix distribution, chopped polypropylene fibers were inserted between the layers of unifabric commingled Jute/PP.

The metallic flat mold is provided of an electrical heating system, controlled by Victor VC9808VOM (VoltOhm-Milliammeter) and Tholz Mvh411n P327 temperature controller. The consolidation cycle was previously defined based on the thermal characterization and follows the parameters presented in Figure 3 and Figure 4 the apparatus used for processing the laminate. For consolidation, a hydraulic press machine (SL-12 Solab Scientific) with press capacity of
100 ton $/ \mathrm{m}^{2}$ was used. The machine was adjusted to provide pressure of $20 \mathrm{ton} / \mathrm{m}^{2}$ (empirically defined as the maximum pressure admissible to avoid the matrix leakage), which was kept constant until the temperature of $60^{\circ} \mathrm{C}$ was reached. Finally, the composite preform was released.

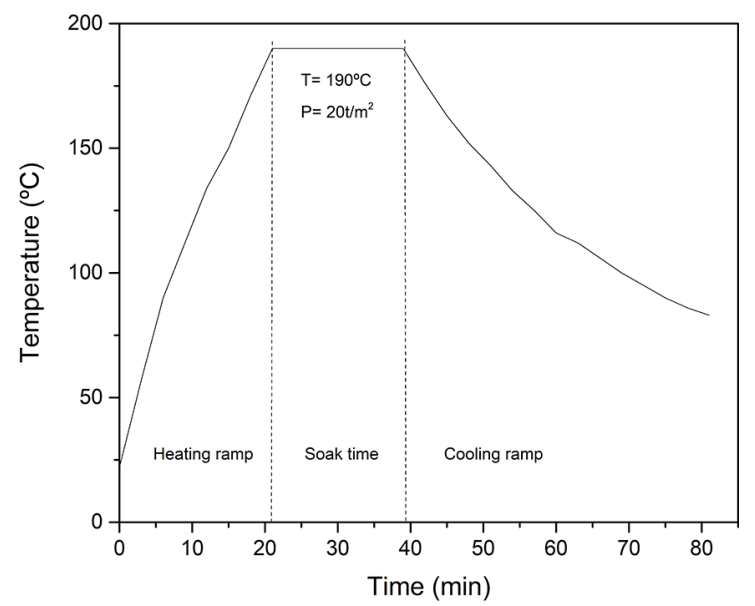

Figure 3. Processing cycle. Bibliographic source: Author.

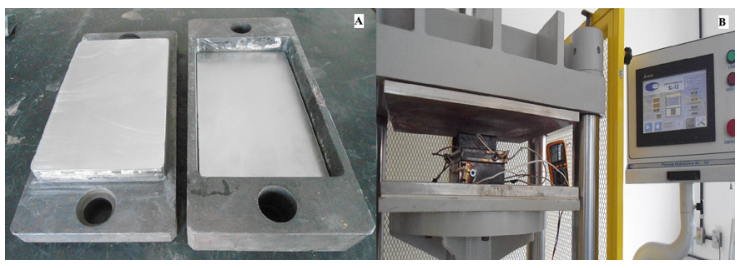

Figure 4. Equipment for under pressured consolidation. (A) Rectangular flat mold. (B): Hydraulic press. Bibliographic source: Author.

\subsection{Mechanical analysis of the Jute/PP composite}

Tensile strength tests were performed according to ASTM D3039 ${ }^{18}$. In this case, a universal test equipment (Instron 8801) combined with an Advanced Video Extensometer (AVE) was used for the tensile test. The elasticity modulus was calculated by Digital Image Correlation (DIC). The specimens were cut in the dimensions of $250 \mathrm{~mm}$ x $25 \mathrm{~mm}$ x $4 \mathrm{~mm}$ by a CNC ROUTER SHG1212, as shown in Figure 5.

After the composite tensile tests the specimens presented a fracture aspect as shown in Figure 6. Fractographic analysis after tensile strength testing were performed by scanning electron microscopy (SEM) in a microscope Zeiss EVOMA15. Then the specimens had the fracture surface protected and cut with a diamond disc and finally, the surfaces were coated with a gold film by sputtering process.

\section{Results and Discussion}

\subsection{Chemical characterization of the PP matrix}

Figure 7 shows the ATR-FTIR spectra of the polymeric matrix. The bands at $2952 \mathrm{~cm}^{-1}, 2917 \mathrm{~cm}^{-1}, 2869 \mathrm{~cm}^{-1}, 2838$ $\mathrm{cm}^{-1}$ are respectively associated with $\mathrm{CH}_{2}$ asymmetrical 


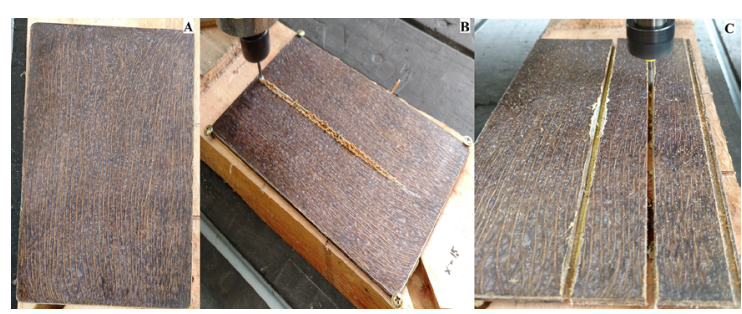

Figure 5. Jute/PP composite plate. (A) Jute/PP composite after processing. (B): Jute/PP composite plate cutting test on $\mathrm{CNC}$ machine. (C): Tensile testing specimen machining. Bibliographic source: Author.

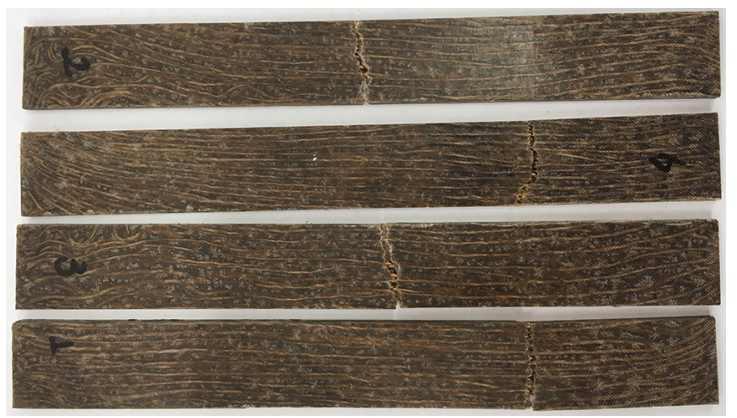

Figure 6. Fracture aspect. Bibliographic source: Author.

stretching vibration, $\mathrm{CH}_{3}$ asymmetrical stretching vibration, $\mathrm{CH}_{3}$ symmetrical stretching vibration and symmetrical $\mathrm{CH}_{2}$ stretching vibration. These bands are presented in PP polymer main chain. The bands at $1454 \mathrm{~cm}^{-1}$ and $1376 \mathrm{~cm}^{-1}$ refers to deformation vibration asymmetrical and deformation vibration symmetrical of the $\mathrm{CH}_{3}{ }^{19,20}$.

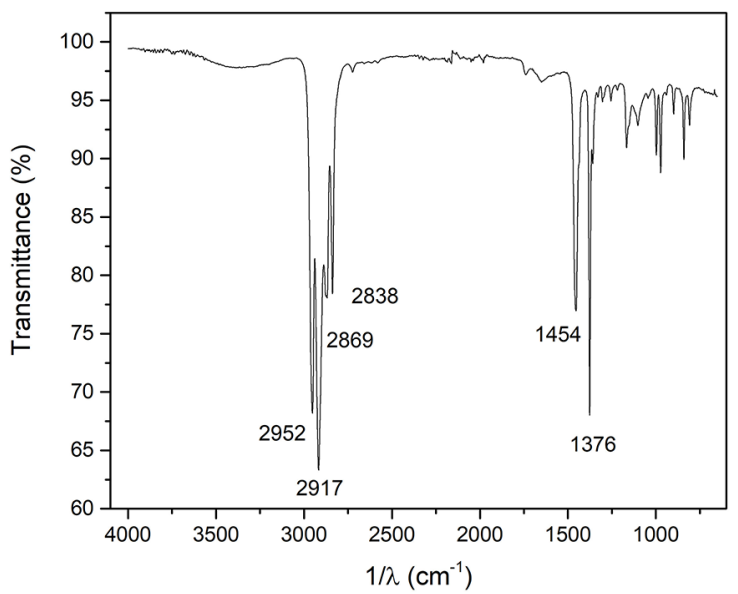

Figure 7. ATR-FTIR spectra of the polymeric matrix. Bibliographic source: Author.

The ATR-FTIR spectrum of the PP also shows numerous small peaks in the wavenumber range $1400-750 \mathrm{~cm}^{-1}$. Bands between $1300 \mathrm{~cm}^{-1}$ and $765 \mathrm{~cm}^{-1}$ refer to carbon lattice pulsation, and at $1302 \mathrm{~cm}^{-1}, 1224 \mathrm{~cm}^{-1}, 941 \mathrm{~cm}^{-1}$. Bands $1357 \mathrm{~cm}^{-1}, 1328 \mathrm{~cm}^{-1}$ wagging vibration of $\mathrm{CH} 2-\mathrm{CH}, \mathrm{CH}_{3}$, $1170 \mathrm{~cm}^{-1}$ and $1153 \mathrm{~cm}^{-1}$ deformation vibration of $\mathrm{CH}_{2}$ and
$\mathrm{CH}^{19,20}$. The bands present in PP spectrum confirms that the yarn is made of polypropylene (PP) $)^{19,20}$.

\subsection{Thermal characterization of the PP matrix}

Figure 8 shows the polymer DSC analysis results. Run 1 was obtained by heating the sample from 25 to $250^{\circ} \mathrm{C}$ and presents an endothermic peak at $161.25^{\circ} \mathrm{C}$ associated with the melting point of the PP sample. This temperature, therefore, is the minimum required for the compression molding of the composite once it requires low viscosity to properly wet the fibers. The area below the peak represents the melting enthalpy, defined as $75.89 \mathrm{~J} / \mathrm{g}$. Run 2 is the cooling cycle from 250 to $25^{\circ} \mathrm{C}$ and shows an exothermic peak at $122.35^{\circ} \mathrm{C}$ due to the crystallization of the sample. This value indicates the minimum temperature at which the composite can be removed from the flat mold after the consolidation. The PP is in a solid state below $122.35^{\circ} \mathrm{C}$.

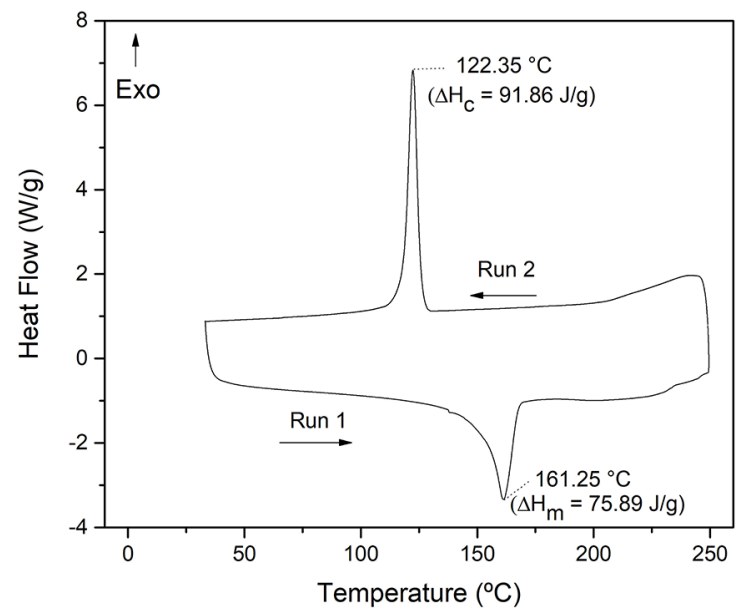

Figure 8. Polypropylene DSC analysis. Bibliographic source: Author.

As stated before, the degradation of natural fibers can be a limiting factor for the process of composite materials reinforced by them. Therefore, Figure 9 presents the TG/ DTG results for the $10^{\circ} \mathrm{C} / \mathrm{min}$ analysis. The TG curve has three steps of thermal degradation, as described in Table 2.

From the results presented both in the Figure 9 and Table 2, the upper limit of the processing temperature is defined by the onset of the hemicellulose and cellulose degradation $\left(254^{\circ} \mathrm{C}\right)$. This temperature is also related to the maximum degradation degree $(\alpha)$ that can be reached during the processing of the composite without compromising the final product quality by starting the decomposition of the hemicellulose and cellulose degradation.

Based on these temperature and degradation limits, the Friedman's isoconversional kinetic model was used to calculate the activation energy (Ea) as a function of the degradation degree, and to define the processing window by forecasting the time at which the jute fiber reaches $10 \%$ $(\alpha=0.1)$ of degradation in the temperature range from 160 


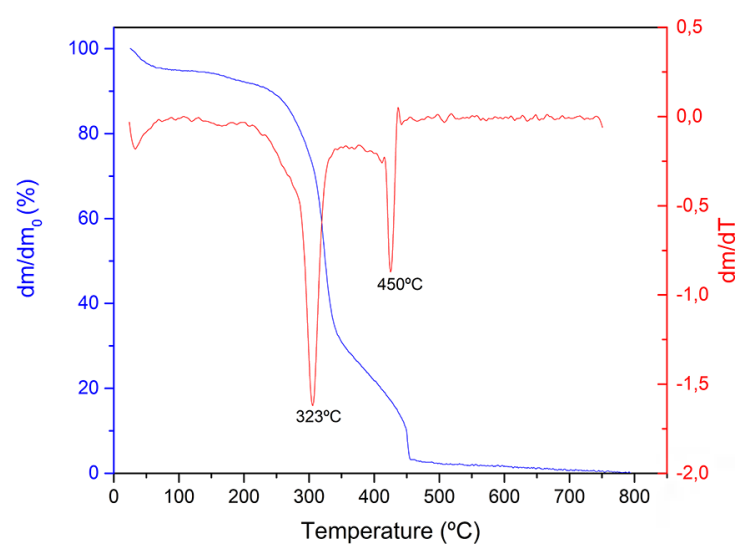

Figure 9. TG/DTG curves of jute fiber. Bibliographic source: Author.

to $260^{\circ} \mathrm{C}$. The calculation of kinetic parameters and the forecast were made from the TGA results at three different heating rates presented in Figure 10.

The average activation energy $(\mathrm{Ea})$ obtained for the jute fiber degradation is $(159.51 \pm 64.62) \mathrm{kJ} / \mathrm{mol}$. This average value was calculated considering the degradation degree range from 0.1 to 0.99 , and it is in accordance with values previously obtained in literature ${ }^{22}$. The high standard deviation occurs because the mechanism of reaction of natural fibers can change in both too low $(<0.1)$ or too high $(>0.7)$ degradation degrees ${ }^{14}$.

This change of mechanism also leads to difficulties in modeling the entire process of natural fiber degradation, limiting the precision of models depending on the degradation degree. For the chosen limit of degradation, the coefficient of determination is about $70 \%$, providing a good estimated forecast of the degradation behavior for the jute fiber as a function of both time and temperature, as shown in Figure 11.

According to the forecast in Figure 11, the composite reinforced with jute fiber can be processed in the range from $160^{\circ} \mathrm{C}$ (approximate melting point for the PP matrix) from $260^{\circ} \mathrm{C}$ (onset for the hemicellulose and cellulose degradation) during 35 to $10 \mathrm{~min}$ without reaching a compromising degradation degree. Based on that result, and considering the effects of heat distribution in large parts, the temperature cycle for the Jute/PP composites was established as described in Table 3.

Even though the polymer matrix melting onset was determined by DSC as $\sim 160^{\circ} \mathrm{C}$, the temperature chosen for the soak stage was $190^{\circ} \mathrm{C}$. This choice was also made considering the heat distribution that may differ from the DSC sample to the larger composite part under processing cycle. The higher temperature is, therefore, chosen to prevent

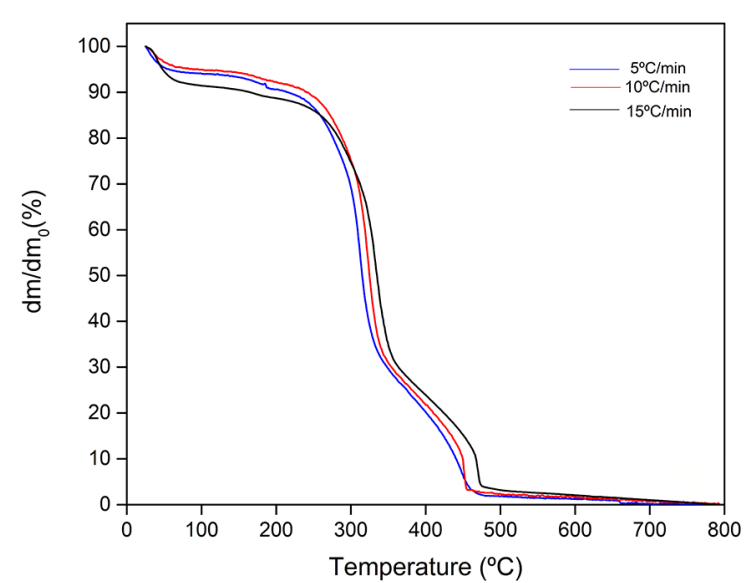

Figure 10. TG curve of jute fiber at different heating rates. Bibliographic source: Author.

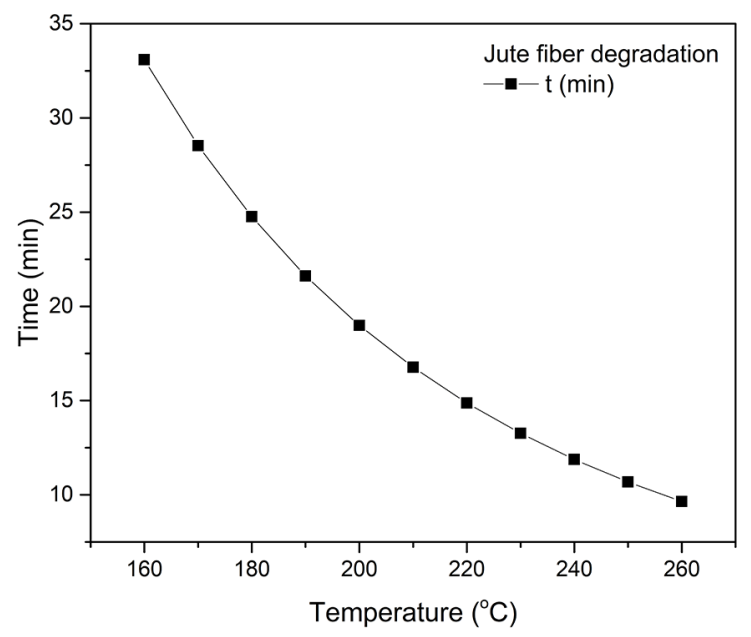

Figure 11. Jute fiber degradation. Bibliographic source: Author.

the incomplete melting of certain regions of the composite matrix, assuring the uniformity of the final part.

\subsection{Mechanical properties of the jute fiber}

Table 4 shows the values obtained from the jute yarn tensile test. The tensile strength and the elasticity modulus obtained to a multi filament sample were respectively 78.84 $\mathrm{MPa}$ and 27.46 GPa. Even though the elasticity modulus value is in accordance with the literature ${ }^{23}$, it was observed that the tensile strength has showed values lower than the expected $^{24,25}$. This result may be related to the variability of the natural fibers properties that are dependent on the plant growth conditions ${ }^{26}$ and to the fact that the fiber yarn

Table 2. TG degradation steps of Jute. Bibliographic source: Author.

\begin{tabular}{ccccc}
\hline Step & Temperature range $\left({ }^{\circ} \mathbf{C}\right)$ & $\mathbf{T}_{\text {onset }}\left({ }^{\circ} \mathbf{C}\right)$ & $\mathbf{T}_{\max }\left({ }^{\circ} \mathbf{C}\right)$ & Associated event \\
\hline $\mathbf{1}$ & $40-100$ & - & - & Moistures evaporation ${ }^{14,21}$ \\
$\mathbf{2}$ & - & 254 & 323 & Hemicellulose and cellulose degradation $^{14,21}$ \\
$\mathbf{3}$ & $350-450$ & - & 450 & Lignin degradation $^{14,21}$ \\
\hline
\end{tabular}


Table 3. Thermal cycle for Jute/PP composites molding process. Bibliographic source: Author.

\begin{tabular}{cccc}
\hline Stage & Heating rate $\left({ }^{\circ} \mathbf{C} / \mathbf{m i n}\right)$ & Temperature range $\left({ }^{\circ} \mathbf{C}\right)$ & Time $(\mathbf{m i n})$ \\
\hline Heating ramp & 8 & $25-190$ & 20 \\
Soak Time & - & 190 (Constant) & 21 \\
Cooling ramp & 2 & $190-120$ & 40 \\
\hline
\end{tabular}

Table 4. Jute fiber mechanical properties. Bibliographic source: Author.

\begin{tabular}{lccc}
\hline Measures & Tensile strength $\mathbf{( M P a )}$ & Elongation $\mathbf{( m m} / \mathbf{m m})$ & E (GPa) \\
\hline Samples & 15 & 15 & 15 \\
Average & $78.84 \pm 10.74$ & $2.88 \pm 0.19$ & $27.46 \pm 4.65$ \\
\hline
\end{tabular}

is formed by a group of several twisted filaments. These factors may have some contribution in limiting the composite mechanical properties.

\subsection{Mechanical properties of the Jute/PP composite}

Tensile strength tests were performed with load applied in the same direction of the fibers. The measurements results are shown in Table 5, which also includes the elasticity modulus values obtained by DIC.

Table 5. Composite mechanical properties. Bibliographic source: Author.

\begin{tabular}{ccc}
\hline Measures & $\begin{array}{c}\text { Tensile strength } \\
(\mathbf{M P a})\end{array}$ & E (GPa) \\
\hline Specimen 1 & 47.45 & 9.61 \\
Specimen 2 & 40.57 & 7.12 \\
Specimen 3 & 51.69 & 7.69 \\
Specimen 4 & 38.75 & 3.98 \\
Average & $44.62 \pm 6.02$ & $7.10 \pm 2.34$ \\
\hline
\end{tabular}

It is well known that the amount of fiber volume in composite influences in the mechanical properties of composite ${ }^{27}$. The Jute/PP composite manufactured by commingled technology presents a fiber volume of $39.8 \pm 5.8 \%$. According to other researches, uncontinuous fiber Jute/PP composites, with $30-40 \%$ fiber volume showed tensile strength $38 \mathrm{MPa}$ and $34 \mathrm{MPa}$ the elasticity modulus $6.4 \mathrm{GPa}$ and $6.8 \mathrm{GPa}$, respectively ${ }^{23}$. From the results presented in Table 5 , it can be noticed that the mechanical properties are slightly better than the ones found in literature, due to the fiber alignment, homogeneity of fiber dispersion in the matrix.

The tensile strength of composite materials is directly linked to the strength and modulus of the fibers used as reinforcement, fiber content, orientation and length, as well as individual matrix properties and fiber/matrix interfacial adhesion. These variability factors can justify the fact that the mechanical properties obtained for the Jute/PP composite are lower than the expected for continuous natural fiber composites $^{27}$. Other reasons for the literature deviation is that both PP polymeric matrix and jute fiber present a large range of mechanical properties. The matrix tensile strength variability is based on its molecular structure varying from 30-40 $\mathrm{MPa}^{23}$ while the jute fibers properties are dependent on the growth conditions, as stated previously.

Figure 12 shows representative photos of these laminates after their respective processing. The visual inspection of these laminates signals the presence of fiber misalignment mainly at the edges of the laminate.

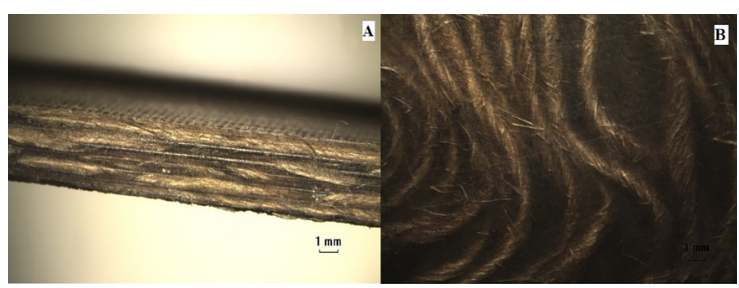

Figure 12. Aspects of optical stereoscopy of the Jute/PP composites. (A): compacting quality of the specimen. (B): Fiber misalignment. Bibliographic source: Author.

The consolidation quality aspect of the Jute/PP composite was also analyzed by optical stereoscopy. The micrograph shown in Figure 12(A) is representative of the quality standard obtained after consolidation of the Jute/PP layers.

From the analysis of Figures 12 (A) and (B) it is observed that the layers of thermoplastic composites are well compacted with a relatively homogeneous fibers distribution. These characteristics are desired because they are directly related to better mechanical and physical properties of the processed materials. However, a certain misalignment was observed at the edges of the specimens, probably due to processing, as shown in Figure 12 (B).

Figure 13 presents the fracture surfaces of the specimens tested under axial tension. In composite materials, the surface tensions that emerge on the surface of the fibers together with the deformation of the polymer matrix during the mechanical loading of the laminate occur due to the difference in fiber and matrix elastic properties. In this case, the effective transfer of stresses from the matrix to the reinforcement is mainly linked to the adhesion at the fiber/matrix interface. Thus, the characteristics of the interface formed have great importance 


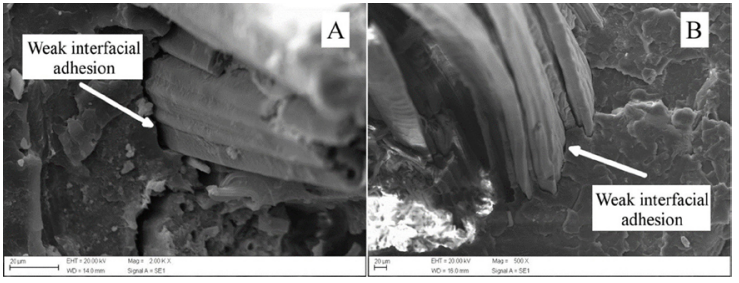

Figure 13. SEM of fracture surfaces of Jute/PP composites. (A): Weak interfacial adhesion (2000x). (B): lack of pretreatment on the surface of the jute fibers (500x). Bibliographic source: Author.

in the mechanical performance of the composite, as they influence the failure process of the composite materials.

Figure 13 (A) reveals an interfacial fiber/matrix region clearly showing the lack of adhesion between these two constituents. Jute fibers, like all lignocellulosic fibers, have in their structure bonds formed by -OH groups. Such bonding tends to render these materials more hydrophilic and consequently more susceptible to moisture, thereby impairing the dimensional stability of the composite. Moreover, the polar bond tends to hinder the interaction of this type of fiber with apolar matrices, interfering in the fiber / matrix interfacial adhesion. Thus, for a good interface to be formed, a pretreatment must be done with coupling agents or compatibilizers on the surfaces of the fibers ${ }^{28}$. As in this work, jute fibers were used as received, it is probable that the lack of adhesion represented by Figure 13 (B) is related to the absence of a pretreatment on the surface of jute fibers.

Fractographic analysis of the region represented by the images of Figure 14 (A), (B) reveals characteristics of pure axial tension loading failure, characterized by the large number fibers pull-out present in the fracture surface of the laminate. In the tension failure, the fracture is characterized by failure of fibers, accompanied by matrix fragile fracture. Also, during tensile loading, the fractures related to matrix can present different aspects depending on the tension rate, being slow-ductile, intermediate-brittle and fast-brittle ${ }^{29}$. In this case, the appearance of the matrix observed in the Figure $14(\mathrm{C})$ presents a characteristic of fast-brittle fracture and is associated with the tensile load velocity, since, the fibers fail before the fracture and the released energy is insufficient to propagate the failure at the same level of applied stress.

Fibers misalignment is shown in the Figure 14 (D) positioned transversally to the fiber alignment and must have occurred during the compression process. In this case, the misalignment is linked to the degree of interweaving of the fabric which during processing tends to deform or bend in a regularly.

Fibers misalignment and poor interfacial fiber/matrix adhesion as well as matrix and fiber properties are the mainly reasons for the lower mechanical properties compared with the continuous natural fiber composites.

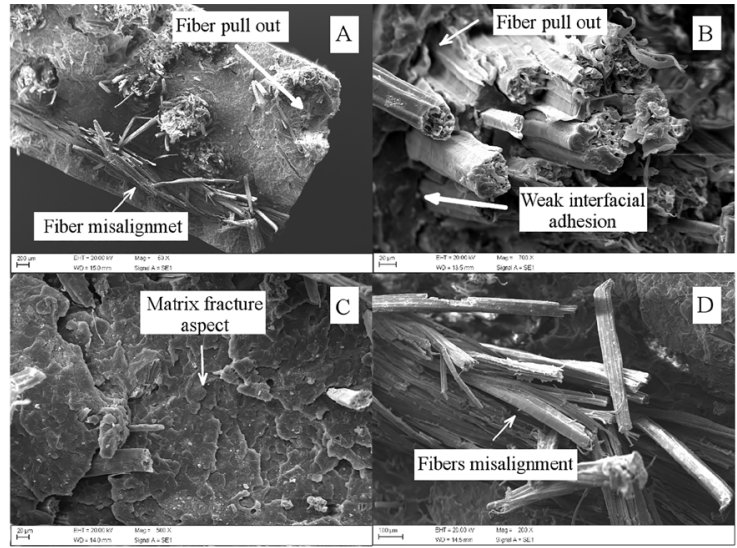

Figure 14. SEM of fracture surfaces of Jute/PP composites. (A): Fiber pull out and fiber misalignment (50x). (B): Fiber pull out and weak interfacial adhesion (700x). (C): Matrix aspect after fracture(500x). (D): Fiber misalignment (200x). Bibliographic source: Author.

\section{Conclusion}

The developed commingled process has shown itself to be a simple alternative for manufacturing of thermoplastic composites reinforced with natural fibers. The low cost and relative simplicity required for combining its use with other conventional processing technologies, like compression molding, makes it suitable for industrial application.

The commingled technique was successfully applied in the manufacturing of Jute/PP commingled composites by compression molding. The final composites presented moderate mechanical properties of tensile strength (44.62 $\mathrm{MPa}$ ) and elasticity modulus (7.1 GPa). These values suggest its possible application in non-structural components for reducing weight, costs and environmental impact. The unifabric of Jute/PP has also presented interesting properties of malleability and strength required by textile industries for weaving processes.

Some possibilities of mechanical properties optimization are: modification of the fiber's surface by chemical treatment or by adding coupling agents; improving process conditions to ensure fiber alignment and using raw materials with improved properties. Along with these improvements, commingled technology can spread the range of possibilities for processing and application of natural and more sustainable composite materials.

\section{Acknowledgment}

The authors are grateful to CAPES, FINEP and NTCUNIFEI for the financial supports.

\section{References}

1. EADS. Part I: The Composite Material Research Requirements of the Aerospace Industry. The research requirements of the 
transport sectors to facilitate an increased usage of composite materials. 2004;1-20.

2. Ye L, Friedrich K, Kästel J. Consolidation of GF/PP commingled yarn composites. Applied Composite Materials. 1994;1(6):415429 .

3. Choi B, Diestel O, Offermann P. Commingled CF/PEEK Hybrid Yarns for Use in Textile Reinforced High Performance Rotors. In: Proceedings of $12^{\text {th }}$ International Conference on Composite Materials (ICCM); 1999 Jul 5-9; Paris, France.

4. West BPV, Pipes BP, Keefe M, Advani SG. The draping and consolidation of commingled fabrics. Composites Manufacturing. 1991;2(1):10-22.

5. Silva JFMG. Pré-impregnados de matriz termoplástica: fabrico e transformação por compressão a quente e enrolamento filamentar [Tese] . Porto: Universidade do Porto; 2005.

6. West BPV, Pipes BP, Keefe M, Advani SG. The consolidation of commingled thermoplastic fabrics. Polymer Composites. 1991;12(6):417-427.

7. Ijaz M, Robinson M, Wright PNH, Gibson AG. Vacuum Consolidation of Commingled Thermoplastic Matrix Composites. Journal of Composite Materials. 2007;41(2):243-262.

8. Cavalcante JMF, Carvalho LH. Estudo comparativo das propriedades mecânicas de compósitos pp / fios alinhados e contínuos de juta. In: Proceedings of $10^{\text {th }}$ Congresso Brasileiro de Polímeros; 2009 Oct 13-17; Foz do Iguaçu, PR, Brazil.

9. Pickering KL, Efendy MGA, Le TM. A review of recent developments in natural fibre composites and their mechanical performance. Composites Part A: Applied Science and Manufacturing. 2016;83:98-112.

10. Hojo T, Xu Z, Yang Y, Hamada H. Tensile Properties of Bamboo, Jute and Kenaf Mat-reinforced Composite. Energy Procedia. 2014;56:72-79.

11. de Paula PG. Formulação e caracterização de compósitos com fibras vegetais e matriz termoplástica. Campos dos Goytacazes: Universidade Estadual do Norte Fluminense Darcy Ribeiro (UENF); 2011.

12. George G, Joseph K, Nagarajan ER, Jose ET, George KC. Dielectric behaviour of PP/jute yarn commingled composites: Effect of fibre content, chemical treatments, temperature and moisture. Composites Part A: Applied Science and Manufacturing. 2013;47:12-21.

13. ASTM International. ASTM E1952-17 - Standard Test Method for Thermal Conductivity and Thermal Diffusivity by Modulated Temperature Differential Scanning Calorimetry. West Conshohocken: ASTM International; 2017.

14. Yao F, Wu Q, Lei Y, Guo W, Xu Y. Thermal decomposition kinetics of natural fibers: Activation energy with dynamic thermogravimetric analysis. Polymer Degradation and Stability. 2008;93(1):90-98.
15. Friedman HL. Kinetics of Thermal Degradation of Char-Forming Plastics from Thermogravimetry. Journal of Polymer Science: Polymer Symposia. 1964;(6):183-195.

16. ASTM International. ASTM C1557-03 - Standard Test Method for Tensile Strength and Young's Modulus of Fibers. West Conshohocken: ASTM International; 2003.

17. Klippel A. Tecelagem Manual. Available from: http://www. tecelagemanual.com.br/Access in: 15/10/2016

18. ASTM International. ASTM D3039 / D3039M-14 - Standard Test Method for Tensile Properties of Polymer Matrix Composite Materials. West Conshohocken: ASTM International; 2014.

19. Morent R, De Geyter N, Leys C, Gengembre L, Payen E. Comparison between XPS-And FTIR-analysis of plasma-treated polypropylene film surfaces. Surface and Interface Analysis. 2008;40:597-600.

20. Urbaniak-domagala W. The Use of the Spectrometric Technique FTIR-ATR to Examine the Polymers Surface. Advanced Aspects of Spectroscopy. 2012;86-104.

21. Cogswell FN, Leach DC. Processing science of continuous fibre reinforced thermoplastic composites. Sample Journal. 1988;24(3):11-14.

22. Di Benedetto RM, Gelfuso MV, Thomazini D. Influence of UV Radiation on the Physical-chemical and Mechanical Properties of Banana Fiber. Materials Research. 2015;18(Suppl. 2):265272.

23. Uawongsuwan $P$, Yang Y, Hamada H. Long jute fiber-reinforced polypropylene composite: Effects of jute fiber bundle and glass fiber hybridization. Journal of Applied Polymer Science. 2015;132(15):41819.

24. $\mathrm{Ku} \mathrm{H}$, Wang $\mathrm{H}$, et al. A Review on the Tensile Properties of Natural Fibre Reinforced Polymer Composites. Igarss 2014. 2014;(1):1-5.

25. Marinelli AL, Monteiro MR, Ambrósio JD, Branciforti MC, Kobayashi M, Nobre AD. Desenvolvimento de compósitos poliméricos com fibras vegetais naturais da biodiversidade: uma contribuição para a sustentabilidade amazônica. Polímeros. 2008;18(2):92-99.

26. Wambua P, Ivens J, Wambua P, Ivens J, Verpoest I. Natural fibres: can they replace glass in fibre reinforced plastics? Composites Science and Technology. 2003;98(9):1259-1264.

27. Khondker OA, Ishiaku US, Nakai A, Hamada H. A novel processing technique for thermoplastic manufacturing of unidirectional composites reinforced with jute yarns. Composites Part A: Applied Science and Manufacturing. 2006;37(12):2274-2284.

28. Karaduman Y, Onal L. Flexural behavior of commingled jute/ polypropylene nonwoven fabric reinforced sandwich composites. Composites Part B: Engineering. 2016;93:12-25.

29. Purslow D. Fractography of fibre-reinforced thermoplastics, Part 3. Tensile, compressive and flexural failures. Composites. 1988;19(5):358-366. 